\title{
LOS TIEMPOS DEL CINE
}

Por David VERA-MEIGGS*

\section{Prólogo}

Una enferma de Alzheimer deja escapar una frase significativa: "hace mucho tiempo que no hace tiempo...". Raúl Ruiz dice en una conferencia: "Como decía el finado Cortázar, ni vos ni yo, ni Jorge Guillermo Federico Hegel, sabemos lo que es el tiempo". Un niño de seis años que está aprendiendo a leer al contemplar un muro: "... el... Che vi-ve..., ¿Quién es ese?". La hermana de doce años le responde rápidamente: "Uno que está muerto". "Esto que acaba de pasar es muy antiguo", afirma un indígena. Chaplin se demoró mucho en encontrar las soluciones finales de algunas de sus películas, llegando a filmar íntegra de nuevo una de ellas con la siguiente excusa: "El tiempo es el mejor autor, siempre encuentra un final perfecto".

En el futuro podremos estudiar con mayor transparencia la relación existente entre los cambios que la física teórica trajo consigo al pensamiento cultural de los últimos dos siglos. Sabemos de haber cambiado muchos paradigmas inamovibles y de haber creado otros en el último tiempo. La soberbia de crear un progreso irreversible ha ido dando señales de peligro a través de los problemas ecológicos que padecemos, por lo que una cierta desconfianza en la actual lógica ha multiplicado las aprehensiones sobre nuestro destino. Esta época de cambios fulgurantes requiere cada vez mayor cantidad de archivos que den cuenta de todo ello, lo que da como resultado inmediato la fragilidad de la memoria individual, algo ya avizorado por Sócrates en su discurso contra la escritura. Pero no hay razones para suponer que habría tenido las mismas objeciones con respecto al cine. En él se registra una memoria colectiva y objetivada por una mecánica físico-química que le da su materialidad, pero también contribuye a esa memoria del individuo, que en el mejor de los casos no está alienado por los medios de comunicación, sino que los utiliza como parte del desarrollo de la propia conciencia.

Libertad o jaula para la cultura contemporánea, el cine presenta nítido el problema de la existencia temporal. No es lo único que el Séptimo Arte tiende a transparentar, pero sin duda al estar en pleno desarrollo el segundo siglo del cine ya se puede hablar de una experiencia que ha superado varios arcos generacionales. A esos cambios están dedicados estos tres tiempos.

\section{Primer tiempo}

El cine nació a tiempo, en el momento justo, cuando ya el tiempo dejaba de ser el que había sido y comenzaba a relativizarse gracias a Einstein y cuando la desaforada subjetividad individual adquiría carta de ciudadanía gracias a Freud.

Mucho que ver. Ese fue su lema. De ahí sus ínfulas de recién llegado al concierto de la cultura. Hace un más de un siglo el mundo tenía amplias zonas imaginables todavía, y todavía tenía tiempo para explorarlas. La ciencia creía que lo lograría sola, dando de paso la felicidad a los hombres, al menos a aquellos que se creían el cuento del positivismo. Un cuento muy francés, tanto que inventó el cinematógrafo el Día de los Inocentes de 1895 en

\footnotetext{
* Profesor del Instituto de la Comunicación e Imagen. Universidad de Chile
} 
la tarde, en la tarde oscura de un invierno de la Ciudad Luz, que también se creía el cuento de sí misma.

Todo muy correcto y normal, muy científico y muy burgués, muy perfecto y ordenado. La intención original era un poco más racional que aquella que había empleado Edison al inventar, un par de años antes, el kinetoscopio, aparato que fue utilizado en "distracciones" de gusto masivo. Los hermanos Lumiére pretendían en vez contribuir a la ciencia y mostrar escenas documentales carentes de todo énfasis. Desde sus comienzos norteamericanos y europeos tuvieron distintas concepciones sobre lo que valía la pena de ser exhibido con las imágenes en movimiento.

Pero en aquel Día de los Inocentes el Diablo metió la cola. En la sala estaba presente un señor burgués como todos los demás, pero que era la excepción confirmadora de la regla: un prestidigitador llamado Méliès, es decir uno que hacía su fortuna en hacerle creer a todo el mundo lo que en realidad no podía ser. El cinematógrafo sería el instrumento preciso para que el mago se hiciera inmortal, algo todavía más difícil que sacar un conejo de un sombrero.

Todo ocurrió más o menos así: fascinado por lo que había visto en aquella primera proyección el mago se compró una cámara y salió a filmar al centro de París. En eso estaba cuando el aparato se atascó para después volver a funcionar. Al ver proyectado el material nuestro mago se llevó una tremenda sorpresa al descubrir que las imágenes obtenidas sufrían una inquietante transformación, de carretela tirada por caballos a señora de sombrero emplumado. Se cuenta que el mago estuvo tres días tratando de entender el fenómeno, ya que sin saberlo había asistido a la primera síntesis espacio-temporal visible en la historia. Había descubierto el montaje, el que, igual que en otros casos de la historia, sería mejor aprovechado por otros que por él mismo. Sacar un sombrero de dentro de un conejo habría sido menos espectacular.

Sólo entonces comenzó verdaderamente el cine y el tiempo dejó de ser lo que era.

El tiempo no es un problema para reflexionar mientras el lapso de la percepción de un fenómeno es equivalente al desarrollo de éste. Cuando algo se termina y queremos recordarlo el tiempo comienza a hacerse presente, pero aun más cuando adquirimos conciencia de la finitud del fenómeno y su mayor distancia desde el presente. Entonces lo evocado comienza a adquirir un sentido.

La interrupción de la continuidad temporal de la filmación y su posterior reproducción en pantalla nos hicieron tomar conciencia de la facilidad con que el tiempo quedaba atrapado por el mecanismo. Será eso mismo lo que hará evolucionar al aparato tomavistas hacia los dominios del lenguaje primero y del arte después, lo que aumentará sus ya probadas capacidades de convencimiento masivo. Efectivamente es posible deducir que sin dicha síntesis temporal el cinematógrafo hubiese quedado reducido a una pura funcionalidad científica, "para estudiar el vuelo de las aves", como lo pensaban en sus mejores intenciones los Lumiére. Después de la innegable fascinación inicial el público se habría fácilmente fastidiado de la pura imitación. Méliès les propuso la participación imaginativa y el perpetuo movimiento de la pantalla, que perpetuó, no ya el instante, sino que la idea misma del tiempo.

Pero dicha idea se adquiere... con el tiempo.

Cuando la voluptuosa agitación juvenil deja paso a la búsqueda de sentido del propio quehacer es cuando comenzamos a adquirir la conciencia de la finitud, ella es la que nos convence de nuestra ineludible mortalidad. Cuando la imagen interrumpida en su fluir temporal nos mostró la pequeña diferencia entre la pura reproducción mecánica y el germen 
de un nuevo lenguaje, adquirimos súbita conciencia de que toda imagen adquiere sentido en su muerte y en lo que deja como herencia de significado para la imagen siguiente. Toda imagen real (es decir la que se forma en nuestra memoria perceptiva a partir de un estímulo externo) está encadenada al fluir constante, lo que es maravillosamente engañador y ambiguo, porque no logramos advertir hacia donde nos lleva lo que contemplamos en el presente.

Al estar limitada en el tiempo la imagen cinematográfica ha adquirido su sentido definitivo previamente al momento en que nosotros la percibimos, lo que nos protege de todo engaño e incertidumbre sin límites. Nos interesa que la imagen nos cuente el cuento, pero el cuento ya envasado, ya definido en sus alcances, cuyo encanto depende grandemente del hecho de no conocer completamente el desarrollo y asistimos a él como si los hechos estuvieran desarrollándose por primera vez ante nuestros ojos. El hecho de que sepamos que no es así y que el presente cinematográfico ha sido previamente envasado es la razón principal de la seguridad que nuestra conciencia tiene para entregarse incondicionalmente a la tiranía de la ficción, de la cual nos podremos liberar en un determinado momento.

Por lo tanto el cine sería tiempo envasado en una conserva que, al menos por ahora, no tiene fecha de vencimiento.

\section{Segundo tiempo}

Si la eternidad es repugnante a una razón que se sabe limitada, es también deseable por lo mismo. En dicha tensión se incuba la necesidad que todas las sociedades han tenido del arte. Cada una de sus disciplinas han tenido que expresar con sus medios el problema de lo transitorio, por ser inseparable de la experiencia humana. De hecho no hay grupo, por primitivo que sea, que carezca completamente de alguna expresión estética, así sea el uso de una pluma colocada en partes pudendas. La imagen se funda sobre la idea de la muerte, de la ausencia, la que debe ser suplantada por un simulacro que apela más a la psiquis que al mundo físico. Nuevamente encontramos aquí el fenómeno del sentido que algo adquiere cuando cesa de existir en la percepción inmediata y debe recurrir a su recuerdo para volver a hacerse presente. Imagen es re-presentación, es decir, una estrategia para volver al presente lo que ya no está en el presente. La invocación, el rito, el relato mítico, la Edad de Oro, la hipnosis, la regresión, la droga alucinógena, el trance, la música, la danza, la escritura, la recitación épica. Todo es una cifra de la memoria, pero es el cine el que transforma esto en espectáculo democrático y al mismo tiempo en reflexión estética de envergadura.

El descubrimiento del montaje ocupará la atención de los primeros cineastas, que se dedicarán con verdadera obsesión a cortar todo lo cortable y proponerle a su público una realidad altamente manipulada por la necesidad de compensar la falta de sonido, lo que inevitablemente dejaba a la imagen coja de parte de sus significados originales, porque es conveniente recordar que no vemos nada que no escuchemos al mismo tiempo, como tampoco ninguna de las funciones de los otros sentidos se mantienen inactivas durante el proceso perceptivo. La sinergia sensorial es un fenómeno estudiado muy recientemente, pero ya sabemos que las imágenes no son sólo visibles y auditivas, también son olfativas, táctiles y gustativas, sólo que su interrelación aun no está bien delimitada.

El montaje se transformaría en manos de los soviéticos en la razón misma de ser del cine. El más grandioso intento de teorización del nuevo arte encontrará en Sergei Eisenstein a su paladín. Para él el montaje está presente en toda la historia de la comunicación, lo que 
no tenía nada de equivocado, excepto que no era eso lo que constituía la esencia del cine, como él quiso ver hasta un cierto momento. La pintura o la literatura han también creado asociaciones nuevas de fragmentos de la realidad sin por eso pretender encontrar en dicha operación aquello que los justificaba como lenguajes artísticos.

La aparición del sonido hacia finales de la década del veinte pondría las cosas en su lugar. Al tener el apoyo acústico las imágenes no requieren para explicarse la preeminencia del montaje y éste rápidamente cayó en importancia hasta el extremo célebre de "La soga" de Hitchcock, que logró, con no poco esfuerzo, filmar su película en sólo ocho tomas de diez minutos de duración cada una, disimulando los cortes con recursos no siempre felices. El tiempo de la acción duraba exactamente el tiempo de proyección. ¿No existiría el peligro de volver al punto 0 , el de la no conciencia temporal? Hitchcock, que conocía su oficio, supo escabullir el problema a través del hábil manejo del encuadre, dejando siempre algo fuera del campo visual que era aludido desde dentro, de este modo en ningún momento perdíamos la conciencia de estar viendo una parte de un todo mayor. Así la posibilidad de la interpretación quedaba resguardada.

El alargamiento de las tomas, que mucho contribuirá al desarrollo del realismo de los años treinta y cuarenta, va a traer más de alguna complicación teórica a los cada vez más numerosos estudiosos del cine. El edificio teórico del gran Eisenstein va a sufrir una merma de prestigio del que sólo podrá salir con la aparición de "El ciudadano Kane" de Orson Welles en 1941. El joven debutante cineasta, que mucho sabía de teatro y casi nada de cine, para construir su guión siguió una tendencia que venía manifestándose cada vez más en el cine europeo: el de la construcción no lineal del relato. A diferencia del teatro en el cine era muy fácil cambiar de escenario y de época, por lo que hizo del guión un constante racconto de hechos ya sucedidos antes del comienzo de la película. El montaje, como articulación del tiempo cinematográfico, volvió a ser protagonista en gloria y majestad del espectáculo, pero no por mucho. El neorrealismo italiano volvería a la construcción lineal del relato por ser la mejor fórmula para los contenidos que tenía necesidad de transmitir y que eran urgencia de los tiempos.

Sin embargo al acercarse el cine a su medio siglo comienza a adquirir una nueva conciencia de sus capacidades. Entre ellas la de eternizar el presente.

Quien sacará mayores dividendos de esta virtud no será un creador, ni un teórico, ni un productor, sino que una de las mayores estrellas de Hollywood, la que casi involuntariamente se transformará en la demostración de las nuevas ideas sobre el lenguaje. Greta Garbo hizo su última película en el mismo año del debut de Welles. No tenía planificado un retiro definitivo, pero el fracaso de ese filme, sumado a las insatisfacciones de su contrato la alejaron de la pantalla, a la que finalmente optó por no volver, dejando su imagen incólume al sustraerla del natural deterioro del tiempo. Desde entonces su ocultamiento sistemático a los ojos ávidos de las masas la transformaron en la leyenda que sigue siendo. Imposibilitados de asistir a su natural evolución sus miles de fanáticos debieron remitirse a lo que ya había sido y capturado por la memoria incorruptible de la cámara. Ocurrió esto en un período lo suficientemente maduro del cine como para que dejara una estela de misterio y fascinación que ha logrado perdurar, a pesar de que la Garbo es un tipo de mujer que ya no existe, "que ya no se usa", que sus películas en blanco y negro huelen a naftalina y que hoy el sexo está explicitado más allá de lo que nunca la Garbo intentó. Valentino o Jean Harlow, que murieron jóvenes, parecen de un siglo anterior al de la actriz sueca, cuyo estilo neutro de actuación parece estar marcando el futuro de la disciplina. James Dean y Marilyn Monroe alcanzaran el nivel mítico con sus muertes 
dramáticas y sus películas, que los conservan para siempre bellos y glamorosos en un presente eterno que ya nunca más será.

Así el cine va descubriendo su tremenda capacidad de eternizar el presente y de paso de crear, a través de ello, mitos, pero de los verdaderos, de aquellos que conservan oscuros símbolos sociales y sicológicos y que requieren de ritos para ser conservados en la memoria colectiva, porque le resultan portadores de significados indispensables para la sociedad y el individuo que la conforma. La modernidad tecnológica directamente comunicada con el arcano mundo de los orígenes.

La segunda mitad del siglo asiste al espectáculo de sí mismo en los archivos móviles que son las películas. El neorrealismo italiano quería conmover al público de su época para remover conciencias y obligarlas a aceptar la verdad cruda de la postguerra, pero hoy nos sigue afectando a pesar de que los problemas que denunciaba ya han sido, esperemos, en buena parte superados. Gene Kelly, con su sonrisa dentífrica, cantaba bajo la lluvia para distraer a los norteamericanos de sus angustias políticas, de su profunda crisis democrática, pero la película que así lo muestra ha obtenido mayores ganancias en el medio siglo siguiente. Se desplomó el sistema político que había financiado a Eisenstein, pero sus películas no han notado el cambio.

El cine ya ha ganado la clara conciencia de ser más que un reflejo pasivo del tiempo presente, más que una opinión más o menos certera sobre el mundo. El cine se ha vuelto la constatación perfecta de la relatividad del tiempo como orden indiscutido del universo. Y eso gracias a su mecanismo captador del movimiento y a su creciente capacidad de asumir la propia subjetividad, aquella misma que le habría causado náusea a los positivistas Lumiére, pero que igualmente se encontraba latente ya en la célebre primera exhibición.

"Demolición de un muro", fue una de las películas que compusieron el primer programa del cinematógrafo. Su peculiaridad consistió en que después de cumplirse la acción que el título prometía, una inversión en el sentido de la proyección hizo volver el muro a su estado original. El efecto de retroceso causó menos asombro que la pasiva reproducción de la entrada del tren en la estación, pero fue el detonante de la fantasía afiebrada de Méliès y de las infinitas modificaciones que el naciente lenguaje haría sobre el, hasta ese momento inamovible, sentido lineal del tiempo. Hoy ya no nos asombra ver primero el humo y luego el fuego o ver ascender un paracaidista al que se le cierra el paracaídas antes de volver al avión. Antes del cine todo esto era inimaginable.

Cada época ha tenido un tiempo propio y cada una ha creído que el suyo era el tiempo definitivo. Así como el teatro clásico griego se tomaba fácilmente una jornada solar completa para una representación, en la Edad Media los oficios de Semana Santa debían coincidir con lo que la tradición indicaba había sido la duración real de los acontecimientos que conmemoraba.

A medida que los instrumentos técnicos nos permiten elaborar operaciones intelectuales más rápidas o que nos acercan a mundos físicos más lejanos o infinitamente pequeños, nuestra concepción de la causalidad de los hechos también ha admitido novedades que permiten entender la relación entre un hueso paleolítico y una nave espacial que vuela al compás del nostálgico Danubio Azul.

La supresión de fragmentos temporales, operación que en cine llamamos elipsis, forma parte de la experiencia habitual de cualquier espectador de cine, cultivado o menos. La experiencia de ver abrirse una flor en algunos segundos y marchitarse en otros tantos, no es menos extraordinaria que la tremenda síntesis con que Méliès en su momento hizo durar el viaje a la luna en su exitosa película homónima de 1902. Si por el contrario, una lágrima 
se tomaba largo tiempo en descender por el rostro de Juana de Arco en la muda película de Dreyer, ningún espectador se sentía molesto por la falta de realismo de la escena filmada en cámara lenta.

Estas experiencias incomprensibles en otra época o en otra cultura, indican la gran capacidad contemporánea de aceptar imágenes que van más allá de la directa experiencia del mundo físico y de sus leyes. Y eso se lo podemos permitir al cine por ser resultado de una operación científica transformada por la imaginación sensible de un creador. Lo que por lo demás también sucedió durante el Renacimiento, cuando las leyes de la perspectiva crearon la ilusión de una profundidad calculada por una observación matemática perfectamente insertada en la lógica intelectual de aquel tiempo. Está claro que los hermanos Lumiére igual hubieran terminado en la hoguera junto a su aparatito si se les hubiera ocurrido presentarlo en una plaza florentina del siglo XV.

Por eso es que el cine nació a tiempo, cercano al cubismo, un poquito adelantado a la Teoría de la Relatividad y en consonancia con el sicoanálisis, instrumentos que con otros más le abonaron el camino al éxito planetario.

\section{Tercer tiempo}

Pero la alteración del orden natural de los acontecimientos, su dilatación a través de la cámara lenta o su concentración con el acelerado, efectos que el mecanismo de la cámara puede realizar con relativa facilidad, no son el único aporte original que el cine ha entregado al problema del tiempo. Tampoco lo es su capacidad de conservar el presente encapsulado en una eventual eternidad.

Es en la duración del acontecimiento visible donde se esconde su más específica cualidad.

Siendo el cine movimiento, lo que implica tiempo, su articulación como lenguaje va a depender siempre de su capacidad de componer fragmentos temporales. Es ahí donde le ruso Tarkowski encontrará el, a menudo impalpable, material específico del cine.

A mitad de los ochenta aparecerá su libro "Esculpir en el tiempo", que sin pretender más que contener algunas reflexiones sobre el propio trabajo y su visión del cine, logra proponer una alternativa válida a las teorías de Eisenstein. Sin desconocer el gran valor expresivo del montaje, Tarkowski prefiere la toma larga o plano-secuencia en la que la sensación del fluir temporal resulta subrayado, a veces hasta el tedio. En esto sigue las lecciones de Antonioni, Welles, Mizoguchi y otros autores que a partir de la postguerra habían capturado la agonía anímica, de inspiración existencialista, dominante en la conciencia narrativa del mejor cine.

Para Tarkowski el cine en esencia es tiempo atrapado por la cámara y cincelado por el montaje y en el que cada proyección reproduce exactamente la duración que el cineasta ha dejado fijada. La marcación rítmica y temporal ha dado un paso adelante con respecto a la música, cuya intangibilidad material le impide la fijación exacta de la duración de la obra.

Pasolini que veía la percepción real como un plano-secuencia que adquiría sentido definitivo con la muerte, asocia al montaje este otorgamiento de sentido para la imagen cinematográfica, sin que eso anulara la carga subjetiva que significa verlo todo desde un único punto de vista cada vez. Por lo tanto el lenguaje cinematográfico estaría constituido de fragmentos de tiempo sellado, de los que la imagen sería su más evidente constatación. En estos volúmenes temporales es donde se contienen la verdadera forma específica del cine, o específico fílmico, zona medular del fenómeno y que define la capacidad expresiva de cada lenguaje artístico. Así podríamos entender que el montaje de Eisenstein no hacía 
sino responder a la dinámica de sus revolucionarios tiempos, mientras que la lentitud de Tarkowski expresaría la dolida meditación de una crisis espiritual y el sosiego emotivo de tranquila longitud de "Primavera, verano, otoño, invierno... y primavera" del coreano Kim Ki Duk, sería la coherente expresión de una parábola budista en la que el tiempo en un mero accidente en el circular transcurso humano. De la síntesis de todo esto el espectador debería concluir los reales contenidos de las imágenes en movimiento proyectadas en la pantalla de las ilusiones perceptivas, que ya Platón había intuido en el Mito de la Caverna.

Obviamente estos contenidos también están sometidos al transcurrir temporal y nunca nos volvemos a acercar de la misma manera a las mismas imágenes. Heráclito no podría ver dos veces la misma película, lo que podría sí hacer es comprobar lo que hay de permanente entre una experiencia y otra. Aquello que permanece es lo que constituye la verdadera imagen cinematográfica, es decir la que se construye en la psiquis y que es la que verdaderamente permanece en el tiempo, que después de todo es el gran criterio del arte.

¿Cantará Gene Kelly eternamente bajo la lluvia?

\section{Epílogo}

¿Qué sucede con las imágenes cinematográficas, pero de soporte electrónico?

Cuando Hitchcock filmó "La soga" lo hizo como un verdadero desafío a las limitaciones técnicas del cine. No se podía, y aun no se puede, filmar tomas de más de diez minutos de duración debido a las dimensiones de los chasis que cargan el material negativo en una cámara. Por eso intentó disimular los necesarios cortes para crear la ilusión de un contínuo perfecto. Alexander Sokurov, discípulo de Tarkowski, no ha tenido tal dificultad filmando, más bien dicho grabando en video de alta definición, lo que le ha permitido que su obra "El arca rusa" sea efectivamente un largometraje compuesto de una sola larga toma.

El virtuosismo implícito en la operación ha llevado a ciertos excesos, que ven aquí el final del montaje y la elevación de la función mimética del cine a razón primera de su existencia. Pero la obra de Sokurov en realidad no cambia nada, ya que evidencia en todo momento que, cortes o no, la división en secuencias determinadas por la arquitectura del edificio que se recorre, los cambios de época y de personajes cumplen la misma función, lo que reduce la función expresiva de este larguísimo plano-secuencia a una pura y algo redundante exposición de magalomanía esteticista.

Lo interesante de un lenguaje se encuentra menos en la superación de sus posibles límites, sino que más bien en el aprovechamiento de los mismos para decir más de lo que en apariencia pareciera estar destinado.

Cortes más o menos, tecnologías sorprendentes o respeto de la caligrafía clásica, el cine goza de buena salud más por lo que nos sugiere que por lo que explícitamente nos muestra. Por eso es que su capacidad para atrapar un fragmento posible entre todos los fragmentos posibles y eventualmente transformarlo en imagen, es decir un ancla clavada en el fondo de nuestro mar de percepciones, sigue dependiendo de una especificidad temporal. Como mejor percibimos el tiempo es a través de la observación visual de una transformación sufrida por un objeto, es decir un cambio de luz, una transformación constante, una desaparición.

Eso no ha sido cambiado aun por la tecnología nueva que ocupa el cine. Lo que no quiere decir que no hayan indicios que eso pueda suceder. Raúl Ruiz menciona que las imágenes fijas de los fotogramas entregan un tiempo sólido que está hecho también de intercalaciones de oscuridad, por efecto de los necesarios parpadeos del obturador, así a media hora de movimiento se corresponde media hora de oscuridad, de nada proyectada. 
"El tiempo líquido del video es otra cosa"1 ${ }^{1}$, afirma Ruiz y no avanza más en un terreno que podría tener interesantes descubrimientos algún día no lejano. Pero eso sería una elucubración sobre un tiempo futuro, lo que no es nuestro tema... por el momento.

(*) RUIZ Raúl, "Conversaciones con Raúl Ruiz", pág. 26 Edición a cargo de Eduardo Sabrowsky. Ediciones Universidad Diego Portales, Santiago 2003.

\footnotetext{
${ }^{1}$ RUIZ, Raúl, “Conversaciones con Raúl Ruiz”, pag. 26. Edición a cargo de Eduardo Sabrowsky. Ediciones Universidad Diego Portales. Santiago de Chile, 2003.
} 